\title{
Retraction Note: Land use planning in coastal areas based on remote sensing images and big data education resources extraction
}

\author{
Xiaoyan Lei ${ }^{1}$
}

Published online: 23 November 2021

(c) Saudi Society for Geosciences 2021

Retraction Note: Arabian Journal of Geosciences (2021) 14: 1036

https://doi.org/10.1007/s12517-021-07421-8

The Editor-in-Chief and the Publisher have retracted this article because the content of this article is nonsensical. The peer review process was not carried out in accordance with the Publisher's peer review policy. The author disagrees with the retraction.

The original article can be found online at https://doi.org/10.1007/ s12517-021-07421-8.

\section{Xiaoyan Lei}

leiyu20192019@163.com

1 School of Network Engineering, Zhoukou Normal

University, Zhoukou 466000, Henan, China 